\title{
Evaluation of a web-based learning management platform and formative assessment tools for a Medical Parasitology undergraduate course
}

Article

\author{
Rita M Wassef ${ }^{1}$, Fatma Alzahraa A Elkhamisy² \\ Parasitology ${ }^{1}$ and Pathology ${ }^{2}$ Departments, Faculty of Medicine, Helwan University, Cairo, \\ Egypt
}

\begin{abstract}
Background: Medical education for undergraduate students in preclinical sciences is challenging and often described as boring by students. Educators have to find interesting new methods to deliver information and increase students' engagement and performance. The incorporation of new technological tools can help in this regard.

Objectives: This retrospective study investigated two technological tools: Google Classroom learning management platform and Google Quiz Forms for online assessment, as regards students' satisfaction, engagement, and performance.

Design and Methodology: The same Parasitology course was taught in a classic face-to-face way during the first year of the study and taught by blended learning technique over the second year. The performance of the students of each year was compared and a questionnaire was introduced at the end of the second year to assess the students' satisfaction.

Results: Students who took full advantage of these tools showed improvement of their performance (mean= 79 in the assessment versus 83.6 in their final exam $(P=0.01)$ and achieved significantly better scores than those of year-1 and year- 2 in the final exam (mean= 83.6 versus 76.3 and 72.7 respectively, $P<0.001$ ). Among 128 questionnaire respondents, $78.9 \%$ preferred the e-learning, $94.5 \%$ found the Google Classroom easy to use, $76.6 \%$ described it as a time saver for submission of assignments and $96.9 \%$ expressed their wish to continue to use the blended learning as well as the formative assessments in other courses and would recommend it to others. They all agreed that the formative assessments at the end of each lecture helped them in summarizing the delivered topic and consolidated the received information. Conclusion: Use of these mobile-friendly, freely available technological tools in resource-limited higher education institutions is recommended to improve the students' engagement and performance in the preclinical sciences.
\end{abstract}

Keywords: formative assessment; Google classroom; learning management platform; medical education; medical parasitology.

Received: 6 May, 2020, Accepted: 21 May, 2020.

Corresponding Author: Rita M Wassef , Tel.: +20 1005782994, E-mail: rita.wassef@med.helwan.edu.eg

Print ISSN: 1687-7942, Online ISSN: 2090-2646, Vol. 13, No. 2, August, 2020.

\section{INTRODUCTION}

All medical schools in Egypt have recently witnessed a major curricular and pedagogical change, and shifted away from lecture-centered teaching toward student-centered learning. Likewise, efforts to encourage inquiry and self-study, and actively engage students in their learning process have gained much importance in recent years ${ }^{[1]}$. With the improvement of educational technology, web-based learning tools have emerged as valuable resources to improve academic performance and enhance motivation and self-directed learning among the new generation of learners ${ }^{[2]}$. Educational tools have become unlimited $^{[3]}$. Various web-based tools that support student-centered learning have surfaced; they serve as a major contributor to fulfill the needs of diverse learning styles ${ }^{[4]}$. Besides, guidelines for use of these tools are also freely available facilitating exploration for teaching and learning purposes ${ }^{[5]}$.
Learning management system platforms (LMPs) are one of the main web-based technologies directed to support learning in higher education institutions. They provide an online folder for the course management that allows sharing study materials; posting and submitting assignments; connecting and chatting with the tutor outside the limited formal office hours; and participation in other different online learning activities ${ }^{[6]}$. On the other hand, Google Classroom is a free LMP that was launched by Google in May 2014, as a new application for self-learning education. It primarily aims to simplify the process of sharing files; streamlining the creation, distribution, and grading assignments in an environmentally friendly paperless way. This allows teachers to spend more time with their students and less time on the paperwork (https://support. google.com >edu>classroom〉 answer). With its newest improvements, Google Classroom has conveyed new functionality like the ability to add more than one 
teacher, preparing for classes in advance and posting study materials, assignments, and quizzes in a preset timing ${ }^{[7]}$.

Over the past few decades, educational researchers agreed that one way to improve student success is to increase the frequency of examinations. Assessment is important in all forms of learning and proved to enhance students' motivation for learning ${ }^{[8]}$. Formative assessment can be very helpful to both students and educators in identifying deficiencies and allowing for timely interventions ${ }^{[9]}$. Online administration of formative assessments, as a part of the web-based learning tools, has many benefits, including quick access and availability, interactive features, effective use of images, immediate and individualized feedback, and automatic scoring ${ }^{[9]}$. Additionally, freely available online websites can be utilized to develop tailored formative assessments for any learning session ${ }^{[10]}$. Meanwhile, online formative assessments provide timely feedback to learners, often in an asynchronous environment. It is also used to monitor progress and share feedback to both teachers and students. Formative feedback could boost student engagement, increase eagerness to learn, and lead to greater achievement ${ }^{[11]}$.

In today's learning environment, students might be expected to look to the online medium for tools to enhance their learning experience. An important American study ${ }^{[12]}$ based on studying thousands of articles on online education from 1996-2008, suggested that instruction combining online and face to face elements, also known as blended learning, had improved outcomes for college students. Blended learning is an electronic learning (e-learning) approach that integrates the assets of both online and face-to-face learning, creating meaningful interactions between students, teachers, and resources ${ }^{[13]}$. The introduction of blended learning into the curriculum was reported to make teaching and learning more flexible being accessible anytime and anywhere, and it fosters selfstudy and participation of the learners ${ }^{[14]}$.

The worthiness of blended learning has not been adequately explored in the Medical Parasitology field. To the best of our knowledge, until now no Egyptian Medical School has introduced it in their curricula although online distance learning has been recently adopted by many Egyptian medical schools due to the Covid-19 pandemic with no results being published till the date of submission of the current work. Therefore, we have undertaken this pilot study to observe and measure the educational value and effectiveness of this strategy as well as to assess the perception of the learners for possible further implications in other courses. As significant time was needed in setting up the online materials and the formative assessment questions, the extent to which students used these resources, their achievement of better scores, and their perceptions of its usefulness to their learning were evaluated to determine whether this experience should be extended to other courses or not.

\section{MATERIAL AND METHODS}

Study type: This retrospective cohort study was conducted retrospectively by comparing two different pedagogical strategies of a Medical Entomology course and their impact on the final scores.

The context: Helwan School of Medicine, a newly established public Medical School in Egypt, adopts a system-based curriculum with multi-disciplinary integrated courses in each module. Medical Entomology course is an integral part of a 7-week-long Basic Medical Sciences module for first-year students. The course was taught by one pedagogic method to first year students attending the academic year $2017 / 2018$ and by a different method to those attending 2018/2019.

Implementation: During the academic year 2017/2018 (year-1), the Medical Entomology curriculum was taught traditionally with didactic lectures and laboratory sessions. The lectures included the review of medically important arthropods, their main characteristics, and their role in causation and transmission of diseases; these topics were further enforced during the laboratory sessions. Lecture notes were provided at the end of each lecture. While during the academic year 2018/2019 (year-2), the course, with the same contents taught by the same teaching staff, was delivered using online and face to face elements (blended learning). Study materials were provided with all lectures and laboratory sessions, on a web-based Google Classroom platform. The platform also provided a mean of communication between the students and the tutor via the classroom stream, creating a forum that enabled the students to ask questions and getting immediate response from the tutor and allowed further discussion with their colleagues. The platform also had the option of privately messaging the tutor to ask or discuss any feedback concerning assignments. The tutor was notified through the application and by email once a student sent any comment.

Students were given optional access to the webbased platform; submission of assignments online; formative assessment at the end of each lecture; and one online comprehensive formative assessment (OCFA) during the course. All formative assessments, at the end of lectures and comprehensive, were designed using the Google Quiz Forms tool. The OCFA was delivered ten days before the end of the module exam and tested all the learning objectives covered during the course. The assessment questions as well as the final exam questions were of the single best answer, multiplechoice format, and ranged in difficulty from simple recall to advanced problem-solving questions. After each assessment, students could review the questions 
and explanations and track their own activity and progress online. In addition, an analysis and discussion of the questions with the tutor was conducted in the first few minutes of the following lecture.

An online survey for students' feedback was introduced at the end of the course before the final summative assessment. Google Form was also used to develop the questionnaire. The survey questions focused on the students' perception of the use of blended learning and the formative assessment strategy. This was correlated with the students' educational background (high school educational system) to assess the feasibility of introducing technological tools in our curriculum; even though most of our students hadn't received any previous E-learning experience in their high schools. Participation in the survey was voluntary and anonymous.

Results of the students' achievements in both academic years were compared, as well as the final scores of the OCFA takers and the non-OCFA takers.

Data collection and statistical analysis: Data were collected and analyzed using IBM - SPSS software version 24. Comparison between the groups was done using Student t-test for continuous data and Chi-square $\left(X^{2}\right)$ test for categorical data. The level of significance was $P<0.05$.

Ethical consideration: The study complied with Helwan University Ethics Committee Guidelines for research with humans and was approved by Helwan Medical School Ethics committee, organized, and operated according to the declaration of Helsinki (Serial number:15-2019).

\section{RESULTS}

Analysis of assessments: A total of 664 first-year medical students participated in the study. Of these, $30.7 \%(n=204)$ were enrolled in the academic year $2017 / 2018$ (year-1) and 69.2\% $(n=460)$ in the academic year 2018/2019 (year-2). Year-1 students were considered as the control group of this study, as their teaching was by traditional face to face learning and without formative assessments or LMP. On the other hand, all year-2 students (100\%) used the web-based platform to access the study materials; however, not all of them were committed to continuous formative assessments. Only 234 (50.8\%) of them used the platform to submit assignments and $26.3 \%$ $(n=121)$ of them used the OCFA. The rest only accessed the platform to obtain the study materials as textbooks, lecture notes, videos and an atlas.

The overall mean of students' scores in the final exam in year-1 was 76.3 versus 75.6 in year- 2 with no significant statistical difference $(P=0.08)$. On the other hand, year-2 OCFA takers $(n=121)$ achieved significantly better scores ( $m e a n=83.6)$ than their peers in year 1 (mean= 76.3, $P<0.001$ ) and year -2 (mean= 75.6, $P<0.001)$. Moreover, the mean of final scores of year-2 non-OCFA takers $(\mathrm{n}=339)$ was not different than that of year-1 (72.7 and 76.3 respectively, $P=0.06$ ).

When comparing the final grades of the OCFAtakers and non-OCFA takers, a significant positive relation between using the formative assessment and enhancement of the students' performance was obtained. More students achieved grades over $90 \%(=\mathrm{A}+)$ and less failures (=F) in the OCFA-takers group, this difference was again statistically different $(P<0.001)$ (Table 1$)$. The results of the study also showed a significant self-improvement in the results of year-2 students who used the formative assessment. Their mean scores in the OCFA was 79 compared to 83.6 in their final exam $(P=0.01)$.

Correlation between high school background and accession of resources online: All 460 year- 2 students used the Google Classroom platform to access the teaching material. Among these students, 252 had received Egyptian high-school education (Thanaweya Amma). Of these, 81 students (32.1\%) used the OCFA versus $171(67.8 \%)$ who had not done so. A total of 62 students had received British education; of those 25

Table 1: Final grades of OCFA-takers and non-OCFA takers.

\begin{tabular}{|c|c|c|c|c|c|}
\hline \multirow{4}{*}{ Grades } & \multicolumn{3}{|c|}{ Groups } & \multirow{3}{*}{ Total } & \multirow{3}{*}{ Statistical analysis } \\
\hline & \multirow{2}{*}{ Year 1} & \multicolumn{2}{|c|}{ Year 2} & & \\
\hline & & Non-OCFA takers & OCFA takers ${ }^{* *}$ & & \\
\hline & No. (\%) & No. (\%) & No. (\%) & No. (\%) & $P$ values \\
\hline A & $78(38.2)$ & $124(36.6)$ & $72(59.5)^{*}$ & $274(41.2)$ & $P<0.001$ \\
\hline B & $43(21.1)$ & $57(16.8)$ & $15(12.4)$ & $115(17.3)$ & $P>0.005$ \\
\hline C & $33(16.2)$ & $44(13.0)$ & $12(9.9)$ & $89(13.4)$ & $P>0.005$ \\
\hline D & $8(3.9)$ & $28(8.3)$ & $9(7.4)$ & $45(6.7)$ & $P>0.005$ \\
\hline $\mathbf{F}$ & $42(20.6)$ & $86(25.4)$ & $13(10.7)^{*}$ & $141(21.2)$ & $P<0.001$ \\
\hline Total & $204(100)$ & $339(100)$ & $121(100)$ & $664(100)$ & \\
\hline
\end{tabular}


(40.3\%) used the OCFA compared to 37 (59.6\%) who did not. Among the students who received American high school education (total $=20$ ), eight students used the OCFA and 12 did not ( $40 \%$ versus $60 \%$ respectively).

Three of 20 (15\%) students from science, technology, engineering, and mathematics (STEM) schools and four of 23 Saudi Baccalauria students $(17.3 \%)$ used the OCFA. The rest of the students $(n=83)$ with other different educational backgrounds (Iraqi, Sumali, Sirian, Palestinian, etc..) did not use it. The results showed that the highest percentage of students engaged with the online assessment was for those with British and American high school backgrounds. However, these results were not statistically significant $(P>0.05)$ (Figure 1).

Analysis of the online questionnaire: A total of $128(27.8 \%)$ year-2 students responded to the questionnaire. Among the respondents, 49.2\% (n=63) were female and $50.7 \%(n=65)$ were male. By analyzing their High-school educational background, 64\% ( $n=82)$ of the respondents had received Egyptian high-school education (Thanaweya Amma), 19.5\% $(n=25)$ had British education (IGCSE/GCSE), 6.3\% $(n=8)$ American
(SAT), 2.3\% (n=3) STEM education and 7.8\% $(n=10)$ received other high-school educations including $0.8 \%$ $(\mathrm{n}=1)$, International Baccalaureate (IB), 0.8\% $(\mathrm{n}=1)$ French Baccalaureate (BAC) and 6.25\% $(n=8)$ SaudiArabia high-school system (Figure 2).

Overall, $78.9 \%$ of the questionnaire respondents $(\mathrm{n}=101)$ preferred the e-learning, 94.5\% $(\mathrm{n}=121)$ found the Google Classroom easy to use, 76.6\% $(n=98)$ described it as a time saver for submission of assignments and $96.9 \%(n=124)$ expressed their wish to continue to use the blended learning in other courses and would recommend it to others. Interestingly, all the questionnaire respondents agreed that the formative assessments at the end of each lecture and discussing the answers together aided in keeping them alert and helped them in summarizing the delivered topic, and to consolidate the received information. They agreed that these assessments helped to improve their performance, kept them motivated, and aided in selfreflection. When asked about the best criteria they liked about this LMP compared to other LMPs they had tried before, many described it as feasible, accessible at anytime and anywhere, mobile-friendly, and it does not consume much internet data.

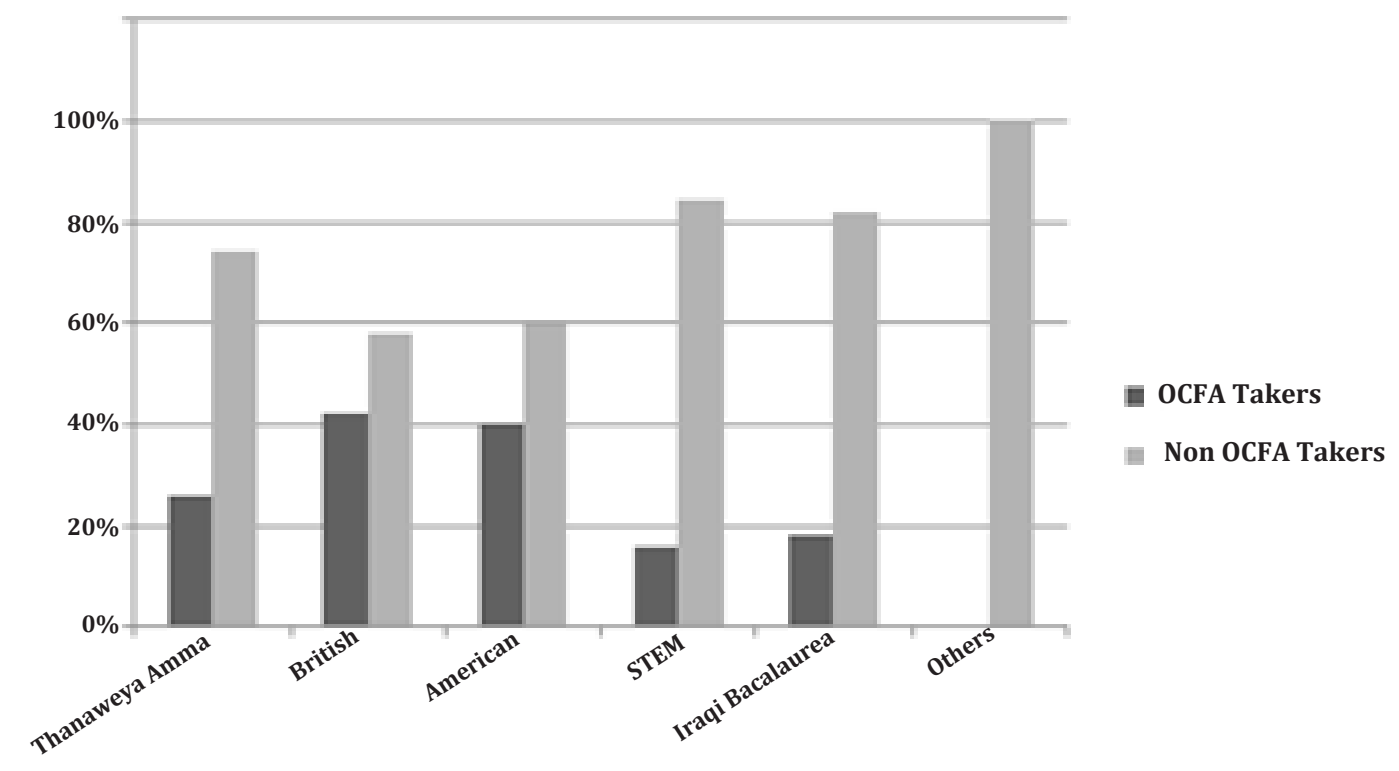

Fig. 1. Engagement of students to the online comprehensive formative assessment (OCFA) according to their high school education background.
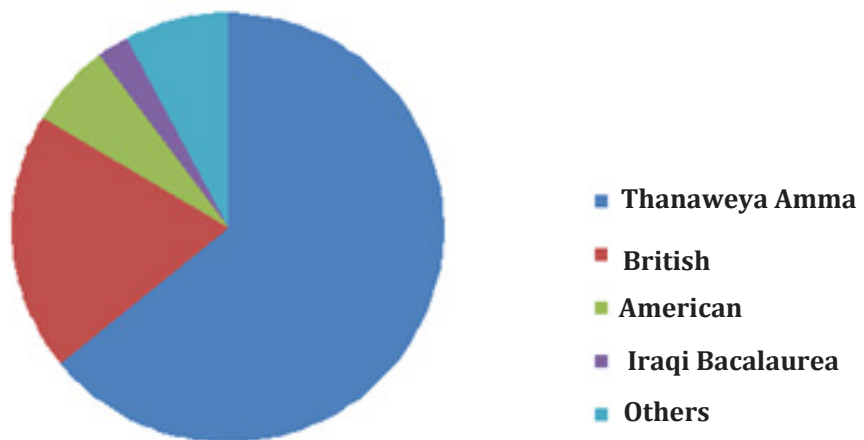

Fig. 2. High school educational system background for the online questionnaire responders. 


\section{DISCUSSION}

The new generation of learners often becomes dissatisfied with outdated traditional teaching methods. They were introduced to technology from a young age and their world revolves around $i^{[15,16]}$. Medical education in the preclinical years is a challenge for educators to find new appealing teaching and assessment methods that increase student engagement and performance ${ }^{[17]}$.

The use of technical advances such as web-based LMPs in Medical Sciences can help in this regards. It was shown to be effective in increasing student engagement, positively impact student academic performance, and provide flexible learning in terms of time and space ${ }^{[18]}$. E-learning resources are increasingly relevant means in higher education to tackle the challenges that human health course in universities are currently dealing with such as larger student cohorts faced by the limited number of teaching staff; the delivery of up to date medical knowledge that is progressively increasing and therefore requires constant adaptation ${ }^{[19]}$. Additionally, the World Health Organization (WHO) and the United Nations (UN) have appreciated the role of e-learning in addressing the increasing shortage of health professionals, which is predicted to increase to 18 million by $2030^{[20]}$, being flexible, interactive and adaptive resource ${ }^{[21]}$.

In this study, we decided to develop available online resources for the entire 2018/2019 class besides traditional lectures, practical sessions, and lecture notes in a seven-week Medical Entomology course. Students were invited to participate in a web-based LMP that included all the essential study materials, a forum for discussion, the option to submit all the assignments online, and getting feedback from the tutor, in addition to continuous formative quizzes. We did not randomize the learners. Instead, they all had a choice to engage in these activities. This study investigated Google Classroom learning management platform and Google Quiz Forms as assessment tools for improving student satisfaction, engagement, and performance.

Interestingly, we found that those who took the full advantage of the online learning element, as indicated by taking the online comprehensive formative assessment, achieved significantly $(P<0.001)$ better scores in the final exam $($ mean $=83.6)$ than their peers in year-1 (mean=76.3) and year-2 (mean=75.6). No significant inter-batch performance differences have been observed, which makes our results reliable. Study reliability is also supported by obtaining similar mean scores with no significant difference for summative exams obtained from non -formative assessment takers in year-2 (Non-OCFA takers), and all students of year-1 who also did not have formative exams at all. Our results are consistent with the literature of Medical Education; students who made use of an online formative assessment and used supplementary tools performed better in summative assessment tasks ${ }^{[9,22,23]}$.

Moreover, there were significantly more students achieving higher scores $(\mathrm{A}+)$ and less failure in OCFA-takers $(P<0.001)$. This may be justified by the fact that students, who profit from different learning opportunities, may be more eager; more motivated and may have better learning habits ${ }^{[2]}$. These "expert learners" take greater responsibility in their achievement outcomes, while actively seeking out opportunities to learn and master selfregulated learning, and eventually they become more prepared for the exam. These qualities lead to better understanding and consequently better outcomes ${ }^{[22]}$. Formative assessments also create a better teaching and learning environment $\mathrm{t}^{[24]}$ especially when technology is blended with them; this helps active engagement of the learners thus increasing students' interactions with content ${ }^{[22,25]}$. It was observed that students' experiences of assessment create an opportunity to learn, hence, supporting the critical role of formative assessment in adult education ${ }^{[10]}$. The inclusion of formative assessments motivates adult learners to achieve better learning outcomes ${ }^{[26,10]}$, and it facilitates the provision of ongoing timely, specific and actionable feedback to learners ${ }^{[27]}$. This is supported by our results.

Furthermore, year-2 students who used the formative assessment (OCFA takers) showed a significant self- improvement as proven by upgrading of their mean scores from 79 in the comprehensive formative assessment to 83.6 in their final exam $(P=0.01)$. This is in accordance with conclusions of previous studies that online formative self-assessments are very effective in promoting student learning and are highly rated in course evaluation surveys ${ }^{[28]}$. If well-designed, formative assessments can improve student motivation and interest to learn. Quizzes with appropriate feedback can help students assess their knowledge and identify areas of weakness, allowing for timely interventions ${ }^{[9,29]}$.

On the other hand, all year-2 students used the Google Classroom platform, although some of them had never used any LMP before. This proves that students are compliant with technology and can adapt to webbased learning. This can be interpreted by the profile of the students of this generation with high IQ, and willing to use technologies provided at their fingertips ${ }^{[16]}$. It is fair to mention that many of today's medical students are pursuing various online study aids ${ }^{[30]}$. However, the majority of our students were not fully aware of the concept of self -reflection for improvement; this is indicated by a lower level of engagement in the online formative exam as well as in responding to the questionnaire in comparison to their participation in the LMP generally, despite their mastering of the same technology learning tool used for both. 
A major consideration while designing a course is the profile of the students ${ }^{[31,16]}$. Society changes and culture shifts affect young generation traits, which become established by the time of joining higher education. These characters may represent special challenges for the medical faculties engaged in their education ${ }^{[32,33]}$. Because of this, we also investigated the relationship between high school background of the students and their ability to use the web-based platform; their perception to using technology in education; and their willingness to engage in formative assessments which can influence their overall performance. There was no significant difference between the students regarding their ability to use the platform. Nevertheless, the highest percentage of students engaged with the online assessment were those with British and American high school backgrounds ( $40.3 \%$ and $40 \%$, respectively) whose programs supported continuous assessment for improvement, in contrast to other programs. This shows that participation in e-learning in higher education institutions can be adopted by all learners regardless of the educational background. In agreement is the previous report regarding the academic performance of students from diverse school types and backgrounds in higher education institutes that proposed school qualifications do not necessarily correlate with the academic potentials ${ }^{[34]}$. Further studies are required to stand upon other reasons that could influence the willingness to engage in blended learning.

In addition, it was indicated that evaluating and monitoring the user`s perception of an e-learning system is an important task to ensure the efficacy of the system ${ }^{[35,36]}$. More than a quarter of our students $(27.8 \%)$ voluntarily participated in the non-obligatory online survey which is considered a good percentage when compared to other studies. For instance in a study ${ }^{[37]}$ conducted in Luxembourg University, only 184 students of a total of 6315 students responded to an online questionnaire and in another survey distributed to all students in five British universities (total number exceeding 40000), only 2456 students responded ${ }^{[38]}$.

In our study, the majority of survey participants appreciated using the Google Classroom platform. Among its advantages the students perceived it as acceptable; easy to use; accessible over the phone as a free mobile application with no need for a desktop. Also, for them it was a time saver for submitting assignments, getting rapid feedback and overcoming routine pathway. They benefited from direct accession of their scores and most of all found it hassle-free being paperless and not limited by time and place. In accordance, Heggart and $Y{ }^{[39]}$ found that Google Classroom increases student participation and learning and improves classroom dynamics.

Similar results were found by introducing Google Classroom in a Biochemistry course for first-year medical students which resulted in student satisfaction.
The authors of this study attributed the satisfaction of their students to better access to the learning resources, the helpfulness of the immediate feedback of their tutors, and the convenience of learning outside of the school environment, with the preference of mobile phones over laptop access ${ }^{[40]}$. Moreover, our results agree with Abou Shosha and his colleagues who found highly significant increased student satisfaction on blending mobile learning tools into a study than doing without $i^{[41]}$. Today many students use smartphones and are attached to their mobiles most of the day; hence, educational tools that are mobile-friendly are perfect methods to interact with their colleagues and teachers ${ }^{[22,43]}$. Similarly, Sulaiman and Dashti ${ }^{[44]}$ reported that their students were very satisfied with using their smartphones for educational purposes.

Technology became involved in medicine with impressive speed. Many medical schools in Europe and the USA have adopted the introduction of technology in their curricula to enable their graduates to become competent physicians of the digital era ${ }^{[45]}$. Teaching in the $21^{\text {st }}$ century medical schools should meet the new changes in terms of technology and student traits to provide the community with a skilled physician who can provide high-quality health care services. Nevertheless, new technological tools necessitate some degree of knowledge for implementation and have some limitations including accessibility, technical support, and updated novel versions required for adaptation of the new features. Applying new technical models into medical education does not necessarily rule out the classical teaching modalities, but rather supports them. Therefore, blended education provides the best chance for students by combining the benefits of both strategies and overcoming their difficulties.

Modern technology as "Google Classroom" that enforces mobile learning, with the associated "Google Quiz Forms tool" for continuous formative assessment in pedagogic education, is preferred by medical students and is more engaging for them. These tools may be particularly useful in resource-limited institutions in low and middle-income countries, to encourage greater access to e-learning and achieving higher academic performance of students.

Authors contribution: Wassef RM designed and implemented the study; and wrote the manuscript. Elkhamisy FA was in charge of the questionnaire, revised and edited the final manuscript.

Acknowledgement: We are grateful for the support of Prof. Dr. Mohamed Fathelbab, Vice-Dean of Education and Students Affairs, Faculty of Medicine, Helwan University, for his valuable support of this work.

Conflict of interest: The authors declared that there were no potential conflicts of interest concerning the research, authorship, and/or publication of this article. 
Financial support: This work did not receive any financial fund from any organization or institution.

\section{REFERENCES}

1. Abdelaziz A, Kassab SE, Abdelnasser A, Hosny S. Medical education in Egypt: Historical background, current status, and challenges. Health Prof Educ 2018; 4(4): 236-244.

2. Bijol V, Byrne-Dugan CJ, Hoenig MP. Medical student web-based formative assessment tool for renal pathology. Med Educ Online 2015; 20: 26765.

3. Han H, Resch DS, Kovach RA. Educational technology in medical education. Teach Learning Med 2013; 25(1): S39-S43.

4. Laurillard D. The teacher as action researcher: Using technology to capture pedagogic form. Stud Higher Educ 2008; 33: 139-154.

5. Pontianak STB. Google Forms: An Assessment Tool Accommodating the Generation-Z Students' Learning Needs. E-Structural 2020; 2(2): 140-152.

6. Lonn S, Teasley SD. Saving time or innovating practice: Investigating perceptions and uses of learning management systems. Comput Educ 2009; 53(3): 686-694.

7. Iftakhar S. Google Classroom: what works and how? J Educ Social Sci 2016; 3: 12-18.

8. Peat M, Franklin S. Has student learning been improved by the use of online and offline formative assessment opportunities? Australas J Educ Tec 2003; 19(1): 87-99.

9. Velan GM, Jones P, McNeil HP, Kumar RK. Integrated online formative assessments in the biomedical sciences for medical students: Benefits for learning. BMC Med Educ 2008; 8:52.

10. Jamil Z, Fatima SS, Saeed AA. Preclinical medical students' perspective on technology enhanced assessment for learning. JPMA 2018; 68: 898.

11. McLaughlin T, Yan Z. Diverse delivery methods and strong psychological benefits: A review of online formative assessment. J Comput Assist Lear 2017; 33, 562-574.

12. Means B. Technology and education change: Focus on student learning. J Res Tech Edu 2010; 42(3): 285-307

13. Jamil Z, Naseem A, Rashwan E, Khalid S. Blended learning: Call of the day for medical education in the global South. SOTL in the South 2019; 3(1), 57-76.

14. Clausen PH, Stelzer S, Nijhof A, Krucken J, SamsonHimmelstjerna G. Established and novel approaches for teaching and learning of veterinary parasitology in Berlin. Vet Parasitol 2018; 252: 58-61.

15. Herrmann FEM, Lenski M, Steffen J, Kailuweit M, Nikolaus M, Koteeswaran R, et al. A survey study on student preferences regarding pathology teaching in Germany: a call for curricular modernization. BMC Med Educ 2015; 15: 94.

16. Buja LM. Medical education today: All that glitters is not gold. BMC Med Educ 2019; 19:110.
17. Badyal DK, Singh T. Teaching of the basic sciences in medicine: Changing trends. Nat Med India 2015; 28 (3), 137-140.

18. Kononowicz AA; Woodham LA, Edelbring S; Stathakarou N, Davies D, Saxena N, et al. Virtual patient simulations in health professions education: Systematic review and meta-analysis by the digital health education collaboration. J Med Internet Res 2019; 21(7):e14676

19. Strube C, Raue K, Janecek E. Simple, but not easy: Opportunities and challenges from teachers' and students' perspectives in the 21st century of veterinary parasitology teaching. Vet Parasitol 2018; 252:74-79.

20. Law GC, Apfelbacher C, Posadzki PP, Kemp S, Tudor Car L. Choice of outcomes and measurement instruments in randomised trials on e-learning in medical education: A systematic mapping review protocol. Syst Rev 2018; 7(1): 75.

21. Fernández-Cruz FJ, Fernández-Díaz MJ. Generation Z's teachers and their digital skills. Comunicar 2016; 24(46): 97-105.

22. Kibble JD, Johnson TR, Khalil MK, Nelson LD, Riggs $\mathrm{GH}$, Borrero JL et al. Insights gained from analysis of performance and participation in online formative assessment. Teach Learn Med 2011; 23(2): 125-129.

23. Kerr S, Muller D, McKinon W, McInerney P. An online formative assessment tool to prepare students for summative assessment in physiology. Afr J Health Professions Educ 2016; 8(1): 72-76.

24. Nicol DJ, Macfarlane-Dick D. Formative assessment and self-regulated learning: A model and seven principles of good feedback practice. Stud Higher Educ 2006; 31: 199-218.

25. Siegle D. Technology Learning Can Be Fun and Games. Gift Child Today 2015; 38: 192-197.

26. Taras M. Assessment-summative and formativesome theoretical reflections. Br J Educ Stud 2005; 53: 466-478.

27. Norcini J, Anderson B, Bollela V, Burch V, Costa MJ, Duvivier R, et al. Criteria for good assessment: consensus statement and recommendations from the Ottawa 2010 conference. Med Teach 2011; 33(3): 206-214.

28. Velan GM, Kumar RK, Dziegielewski M, Wakefield D. Web-based self-assessments in pathology with question mark perception. Pathol 2002; 34: 282284.

29. Ellaway R. Emedical teacher. Med Teach 2008; 34: 259-261.

30. Chen DR, Priest KC, Batten JN, Fragoso LE, Reinfield BI, Laitman BM. Student perspectives on the "Step 1 Climate" in preclinica medical education. Acad Med 2019; 94:302-4.

31. Twenge JM. Generational changes and their impact in the classroom: teaching generation me. Med Educ 2009; 43:398-405.

32. Hunter N, Smith CC, Reynolds EE. Become an effective resident teacher and team leader in 10 tried-andtrue steps. J Grad Med Ed 2018; 10: 488-490. 
33. Maggio LA, Artino AR Jr. Staying up to date and managing information overload. J Grad Med Ed 2018; 10: 597-598.

34. Hoare A, Johnston R. Widening participation through admissions policy: a British case study of school and university performance. Stud High Educ 2011; 36(1): 21-41

35. Shehu V, Besimi A, Abazi-Bexheti L, Shaqiri M. Usability issues while building a new LMS. Proceedings of the 31st International Conference on Information Technology Interfaces, SRCE, Cavtat, Croatia, 2009; 317-322.

36. Orfanou K, Tselios N, Katsanos C. Perceived usability evaluation of learning management systems: Empirical evaluation of the system usability scale. IRRODL 2015; 16(2): 227-246.

37. Chlarb AA, Claßen M, Grünwald J. Sleep disturbances and mental strain in university students: results from an online survey in Luxembourg and Germany. Int J Ment Health Syst 2017; 11, 24.

38. Bolton-Maggs D, Conrad D, Keenan A, Lamden K, Ghebrehewet S, Vivancos R. Perceptions of mumps and MMR vaccination among university students in England: An online survey. Vaccine 2012; 30 (34): 5081-5085.
39. Heggart KR, Yoo J. Getting the most from Google Classroom: A pedagogical framework for tertiary educators. AJTE 2018; 43(3): 140-153.

40. Dash S. Google Classroom as a learning management system to teach Biochemistry in a medical school. Biochem Mol Biol Edu 2019; 47 (4): 404-407.

41. Abou Shosha AA, Mohamed HE, and Fayed SA. Effect of mobile based learning program on postgraduate nursing students' satisfaction and attitudes in Faculty of Nursing Damanhour University. Am J Nurs Res 2019; 8(1): 114-121.

42. Harerimana A, Mtshali NG. Facilitation strategies used in e-learning by nurse educators in Rwanda. Nurs Educ Pract 2017; 8(1): 24-32.

43. Harerimana A, Mtshali NG. Internet usage among undergraduate nursing students: A case study of a selected university in South Africa. Nurs Educ Pract 2018; 8(8): 75-96.

44. Sulaiman A., Dashti A. Students' satisfaction and factors in using mobile learning among college students in Kuwait. EURASIA J Math Sci Tech Edu 2018; 14(7): 3181-3189.

45. Aktekin NC, Çelebi H, Aktekin M. Let's Kahoot! Anatomy. Int J Morphol 2018; 36(2): 716-721. 